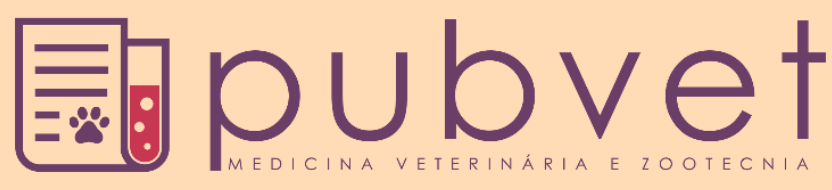

https://doi.org/10.31533/pubvet.v13n10a431.1-6

\title{
Análise microbiológica da água de diferentes fontes da Escola Estadual Agrotécnica Afonso Queiroz
}

\author{
Ricardo Lucas Ferreira Junior $^{1 *} \bullet$, Juliana Borges Pereira ${ }^{2} \bullet$ \\ ${ }^{1 *}$ Acadêmico do curso de Medicina Veterinária do Centro Universitário de Patos de Minas, Patos de Minas -MG Brasil. \\ ${ }^{2}$ Professor do Centro Universitário de Patos de Minas - UNIPAM, Departamento de Medicina Veterinária. Patos de Minas-MG Brasil. \\ *Autor para correspondência, E-mail: juninrlfj@yahoo.com.br
}

\begin{abstract}
Resumo. A água é essencial para a sobrevivência do ser humano e o equilíbrio da natureza. $\mathrm{Na}$ mesma veicula vários microrganismos que podem causar diferentes patologias, sendo necessário o seu controle microbiológico. O objetivo deste estudo foi avaliar a qualidade microbiológica da água de diferentes fontes da Escola Estadual Agrotécnica Afonso Queiroz localizada na cidade de Patos de Minas, Minas Gerais, Brasil. Foram coletadas duas amostras de cada fonte no período matutino e vespertino do poço raso e do córrego Canavial. Utilizando o método de Colilert foi possível identificar coliformes totais, Escherichia coli e a contagem em placa de bactérias heterotróficas. Conclui-se que a água das fontes não estava dentro dos padrões da legislação vigente, devido à presença de pelo menos um microrganismo pesquisado. Assim, a água das fontes não pode ser utilizada para consumo humano; sendo necessária a adoção de medidas preventivas e tratamento adequado, visando à preservação das fontes de água.
\end{abstract}

Palavras chave: água, Escherichia coli, fonte, microbiologia, patologia

\section{Microbiological analysis of water from different sources of the Agrotécnica State School Afonso Queiroz}

\begin{abstract}
Water is essential for the survival of the human being and the balance of nature, though it can hold several microorganisms that can cause different pathologies what makes necessary its microbiological control. The aim of this study was to evaluate the microbiological quality of the water from different sources of the Afonso Queiroz State Agrotechnical School located in the city of Patos de Minas, Minas Gerais, Brasil. Two samples of the shallow well and the Canavial Stream were collected during the morning and afternoon periods. Using the Colilert method, it was possible to identify total coliforms, Escherichia coli and plate counts of heterotrophic bacteria. It was concluded that the water evaluated was not within the standards of the current legislation, due to the presence of at least one microorganism researched. Therefore, the water from the sources cannot be used for human consumption, becoming mandatory the adoption of preventive measures and adequate treatment to preserve the water sources.
\end{abstract}

Keywords: water, Escherichia coli, source, microbiology, pathology

\section{Análisis microbiológico del agua de diferentes fuentes de la Escuela Estatal Agrotécnica Afonso Queiroz}

Resumen. El agua es esencial para la supervivencia del ser humano y el equilibrio de la naturaleza. Igualmente, porta varios microorganismos que pueden causar diferentes patologías, siendo necesario su control microbiológico. El objetivo de este estudio fue 
evaluar la calidad microbiológica del agua de diferentes fuentes de la Escuela Estatal de Agronomía Afonso Queiroz ubicada en la ciudad de Patos de Minas, Minas Gerais, Brasil. Se recolectaron dos muestras de cada fuente durante los períodos de la mañana y la tarde del pozo poco profundo y el arroyo Canavial. Usando el método de Colilert, fue posible identificar coliformes totales, Escherichia coli y recuento en placa de bacterias heterotróficas. Se concluyó que el agua de las dos fuentes no estaba dentro de los estándares de la legislación actual, debido a la presencia de al menos un microorganismo investigado. Por lo tanto, el agua de las fuentes no se puede utilizar para el consumo humano, siendo necesario, la adopción de medidas preventivas y el tratamiento adecuado, con el propósito de preservar las fuentes de agua.

Palabras clave: el agua, Escherichia coli, fuente, microbiología, patología

\section{Introdução}

O planeta terra possui uma superfície composta por água e terra, sendo $70 \%$ de água e apenas $30 \%$ de terra; porém, na realidade a água não é tão abundante. Da água existente no mundo, aproximadamente $3 \%$ é doce e os outros $97 \%$ é salgada. A maior parte da água doce pode ser encontrada nas geleiras e calotas polares, o restante é localizado na forma de gás ou água subterrânea que é encontrada a mais de 800 metros de profundidade; sendo assim, de difícil acesso. A disponibilidade de água para uso, derivada principalmente de rios e lagos, consiste em uma quantidade mínima de apenas 0,01\% de toda água presente no planeta (Ribeiro \& Benedetti, 2012).

A água é essencial para o ser humano sobreviver e tem a finalidade de manter o equilíbrio da natureza. A água é um fator preocupante a nível mundial devido às ameaças de poluição, pelo insustentável uso, do uso do solo, das mudanças climáticas, e dos riscos de escassez. Diante disso, um desafio cada vez maior para continuação da vida e dos processos produtivos é garantir o fornecimento de quantitativo e qualitativo nas áreas rurais e urbanas (Cerqueira et al., 2006).

A água para utilização depende de características desejáveis. Uma água pura e saudável é fundamental para o consumo humano, na finalidade de cumprir esse parâmetro ela deve ser livre de matéria suspensa visível, gosto, odor e cor, de organismos que possa causar enfermidades e de substâncias inorgânicas ou orgânicas capazes de gerar efeitos fisiológicos prejudiciais (Richter \& Azevedo Netto, 2003).

O objetivo deste estudo foi verificar a qualidade microbiológica da água proveniente do córrego Canavial e do poço raso localizados no terreno da Escola Estadual Agrotécnica Afonso Queiroz em Patos de Minas, Minas Gerais, Brasil, verificando a presença de coliformes totais, Escherichia coli e bactérias heterotróficas nas duas fontes de água, respeitando Portaria de Consolidação $\mathrm{N}^{\circ} 5$ de 2017, publicada 28/09/2017 pelo Ministério da Saúde, quanto à qualidade e aos padrões estabelecidos.

\section{Material e métodos}

\section{Local de estudo}

As amostras de água foram coletadas na Escola Estadual Agrotécnica Afonso Queiroz, Fazenda Canavial, Patos de Minas, Minas Gerais, Brasil.

\section{Amostragem}

As amostras foram no córrego Canavial e no poço raso presentes no local, totalizando duas amostras de cada fonte no mês de novembro. As coletas foram realizadas no período matutino e vespertino. As mesmas foram coletadas em recipientes estéreis e transportadas em caixas térmicas. Cada recipiente teve no máximo $100 \mathrm{~mL}$ e foi identificado com o local, data e horário de coleta. As amostras foram encaminhadas ao Laboratório de Microbiologia, localizado no Centro Universitário de Patos de Minas

As análises microbiológicas concordaram com as recomendações da Portaria $\mathrm{N}^{\circ} 5$, de 28 de setembro de 2017, onde foram avaliados os parâmetros de presença/ausência de coliformes totais, termotolerantes 
e Escherichia coli, adotando o teste cromogênico do Colilert ${ }^{\circledR}$. Também foi avaliada a contagem de bactérias aeróbias mesófilas pela técnica de contagem em placa.

\section{Teste de Colilert}

O reagente (Colilert) foi adicionado em um frasco de água contendo $100 \mathrm{~mL}$ de água para todas as amostras coletadas. Esse método é baseado na destruição, pelos coliformes totais, do substrato cromogênico, $\beta$-D-galactopiranosido, pela ação da enzima $\beta$-D-galactosidase a qual está presente nos vários sorotipos de E. coli. Com isso ocorre a liberação de uma substância que altera a coloração do meio (cromógeno o-nitrofenol amarelo forte). Sucessivamente, E. coli tem a enzima 4-metilumbelliferil $\beta$-D-glucoronidase, que quebra a molécula do substrato liberando assim 4-metil-umbelliferil (MUG), que após 24 horas, a uma temperatura de $35^{\circ} \mathrm{C}$, produz intensa fluorescência azul na presença de luz ultravioleta de comprimento de onda $366 \mathrm{~nm}$ (Godinho, 2010).

\section{Contagem de bactérias aeróbias mesófilas}

Para fazer a contagem das placas de microrganismo heterotróficas aeróbias ou facultativas, realizouse elaboradas duplicatas através das diluições de $10^{-1}$ de APT, que foram colocadas no fundo das placas de Petri (técnica de pour plate ou profundidade), e logo após o acrescentamento do Ágar de Contagem Padrão (PCA), fez-se a homogeneização e solidificação. Ficaram incubadas entre 35 a $37^{\circ} \mathrm{C}$, por 24 a 48 horas, em posição invertida. O contador de colônias foi utilizado nas contagens.

\section{Resultados e discussão}

Poluição é uma alteração na relação entre os seres vivos, ou seja, uma alteração ecológica causada pelo ser humano, que pode prejudicar diretamente ou indiretamente, a vida e o bem-estar, acarretando assim malefícios aos recursos naturais, como a água e o solo e impedir algumas atividades econômicas como a agricultura e a pesca (Nass, 2002). Com isso, foram realizados testes de presença/ausência para coliformes totais a fim de avaliar a qualidade dessa água e relatar se está é própria para o consumo humano.

Os resultados para coliformes totais foram insatisfatórios para as amostras do poço raso, uma vez que elas apresentavam contaminação, o mesmo ocorreu com as amostras coletadas do córrego, não estando dentro dos padrões exigidos na legislação. A legislação exige a ausência desses microrganismos em $10 \mathrm{~mL}$ de água. A tabela 1 mostra a presença/ausência de coliformes totais nas amostras analisadas.

Tabela 1. Contagem de coliformes totais em amostras de água, coletadas no córrego Canavial e no poço raso da Escola Estadual Agrotécnica Afonso Queiroz, em novembro de 2018.

\begin{tabular}{llll}
\hline & \multicolumn{2}{c}{ Coliformes Totais } & Presença/Ausência \\
\hline Córrego & Presença/Ausência & Poço & Presente \\
\hline Amostra 1 & Presente & Amostra 1 & Presente \\
\hline Amostra 2 & Presente & Amostra 2 &
\end{tabular}

Valor de referência: Ausente

O mesmo ocorreu tanto no rio Mogi Guaçu, quanto no córrego dos Macacos, sendo a possível causa o lançamento clandestino de esgoto na passagem deste córrego na área urbana de Mogi Guaçu (Madruga et al., 2008). Outros autores constaram poluição microbiológica em micro e pequenas bacias, as quais tiveram ocupação urbana. Todos eles constataram que a poluição ocorreu devido ao esgoto que é lançado nos corpos d'água, sem nenhum tratamento (Almeida et al., 2004; Brites \& Gastaldini, 2007; Giatti et al., 2004; Silveira et al., 2003).

Um estudo avaliou águas subterrâneas no sul do Rio Grande do Sul e 100\% das amostras possuíam coliformes totais. Os autores citaram que diferentes fatores podem influenciar na contaminação do poço como: não fazer a manutenção correta do reservatório, a localização inadequada do poço, a falta de higiene e cuidado com a água antes do devido consumo (Colvara et al., 2009). Em uma avaliação da qualidade da água dos poços raros do munícipio de Colinas, no Rio Grande do Sul, todas as amostras apresentaram contaminação microbiológica, tanto por coliformes totais quanto por $E$. coli. Resultados estes que podem ser explicados devido à má conservação destes poços (Saling et al., 2017). 
Ao analisar a presença de Escherichia coli, os resultados encontrados nas amostras do córrego não foram favoráveis, pois a legislação recomenda que esse patógeno esteja ausente. Nas amostras provenientes do poço raso não houve contaminação. A E. coli foi analisada para observar ou não a presença de coliformes termotolerantes. Os valores estão representados abaixo na tabela 2.

Tabela 2. Presença de Escherichia coli em amostras de água, coletadas no Córrego Canavial e no poço raso da Escola Estadual Agrotécnica Afonso Queiroz, em novembro de 2018.

\begin{tabular}{llll}
\hline & \multicolumn{3}{c}{ Escherichia coli } \\
\hline Córrego & Presença/Ausência & Poço & Presença/Ausência \\
\hline Amostra 1 & Presente & Amostra 1 & Ausente \\
Amostra 2 & Presente & Amostra 2 & Ausente \\
\hline
\end{tabular}

Valor de referência: Ausente

Alguns autores citam que a infiltração da água no período de chuva, proveniente do escoamento das pastagens com fezes de animais, pode contaminar as fontes de água (Coelho, 2001; Llamas \& Custodio, 1982; Narciso, 2003). Os coliformes termotolerantes estão presentes na água quando há a presença de esgotos, significando assim que tem possibilidade de microrganismos patogênicos estarem presentes, devido às pessoas doentes ou portadoras em meio à população a qual deu origem àqueles esgotos (Branco, 2001). A E. coli é uma bactéria que se enquadra como a mais representativa do grupo dos coliformes termotolerantes. Ela habita o trato intestinal de animais homeotérmicos e humanos, por isso quando presente é indicativa de coliformes fecais (Xavier et al., 2014).

O poço raso da escola estava dentro dos padrões qualidade exigido pela legislação. Resultado bem diferente relatado em um estudo, no qual foi observado contaminação por E. coli em todos os poços rasos avaliados (Blank \& Vieira, 2014).

A água do córrego é considerada insatisfatória para o consumo humano, devido a sua contaminação por agentes patogênicos. O mesmo ocorreu no Rio Paranaíba ao avaliar a água em três pontos, constatando-se que a mesma é imprópria para o consumo humano segundo a legislação vigente (Silva et al., 2006). No Rio Itanhém, $72,41 \%$ das amostras apresentaram contaminação por $E$. coli, sendo possível utilizar a água de alguns pontos para o consumo humano (Cunha et al., 2010). A presença de coliformes, dentre eles a E. coli indica que a água foi contaminada por fezes (Chagas \& Veríssimo, 2008).

Quando foi analisada a presença de bactérias heterotróficas, todas as amostras do córrego apresentaram crescimento. As amostras do poço possuíram crescimento mínimo, sendo satisfatórias para o consumo humano, diferente das amostras do córrego que tiveram crescimento significativo destes microrganismos. A tabela 3 relata os valores encontrados.

Tabela 3. Contagem de Bactérias Aeróbias Mesófilas em amostras de água, coletadas no Córrego Canavial e no poço raso da Escola Estadual Agrotécnica Afonso Queiroz, em novembro de 2018.

\begin{tabular}{llll}
\hline \multicolumn{5}{c}{ Bactérias Aeróbias Mesófilas } \\
\hline Córrego & Presença/Ausência & Poço & Presença/Ausência \\
\hline Amostra 1 & $4,60 \times 10^{4}$ & Amostra 1 & $<1 \times 10^{0}$ \\
Amostra 2 & $6,82 \times 10^{4}$ & Amostra 2 & $<1 \times 10^{0}$ \\
\hline
\end{tabular}

Valor de referência: Ausente

As amostras do córrego tiveram alta contaminação por esses patógenos, por isso é insatisfatória para o consumo humano. Um estudo muito parecido foi efetuado, pois todas as amostras coletadas de águas superficiais em um município do estado do Rio Grande do Sul apresentaram contaminação acima do permitido pela legislação vigente (Koch et al., 2017). Pela quantidade apresentada de microrganismos nas amostras coletadas do poço raso, a água desta fonte é satisfatória ao consumo humano, significando assim que não trará riscos a população.

Em um estudo feito na água do manancial subterrâneo em áreas urbanas de Feira de Santana - BA, $71,4 \%$ das amostras apresentaram mais de 500 unidades formadoras de colônias (UFC/ml) em ambas as áreas coletadas. Esse número foi encontrado, pois as amostras coletadas distavam até 10 metros das fossas mais próximas (Silva \& Araújo, 2003). Uma análise microbiológica foi realizada em Cuiabá - 
MT, no bairro Pedra 90, no período de novembro de 2013 a janeiro de 2014, apenas $12,1 \%$ das amostras apresentaram concentrações adequadas desses microrganismos, segundo a legislação referente (Brum et al., 2016). Em Concórdia, foi executada na micro bacia do Lajeado Suruvi, uma análise microbiológica dessa fonte, a qual apresentou níveis de bactérias aeróbicas mesófilas acima do permitido para a legislação vigente, tanto nas amostras coletadas das águas superficiais quanto nas amostras coletadas das águas subterrâneas (Schneider et al., 2008).

É de grande importância o monitoramento da quantidade de bactérias aeróbicas mesófilas, pois em grandes densidades, esses microrganismos na água podem afetar sua qualidade, desenvolvendo sabores e odores desagradáveis, e produção de limo ou películas, fornecendo assim informações sobre a quantidade de nutrientes disponíveis que permitem o crescimento bacteriano e ou a presença de microrganismos patogênicos oportunistas (CETESB, 2011). Vários microrganismos patogênicos, como os vírus, as bactérias e os protozoários, são considerados organismos que não habitam águas subterrâneas, sendo assim, a presença deles indica que houve alguma fonte de contaminação (Cerqueira et al., 2006; Holanda et al., 2016; Oliveira et al., 2012).

\section{Conclusão}

A água das fontes não estava dentro dos padrões da legislação vigente, devido à presença de pelo menos um microrganismo pesquisado. Assim, a água das fontes não deve ser utilizada para consumo humano; sendo necessária a adoção de medidas preventivas e tratamento adequado, visando à preservação das fontes de água.

\section{Referências bibliográficas}

Almeida, R. M. A. A., Hussar, G. J., Peres, M. R. \& Ferriani Junior, A. L. (2004). Qualidade microbiológica do córrego "Ribeirão dos Porcos" no município de Espírito Santo do Pinhal-SP. Engenharia Ambiental, Espírito Santo do Pinhal, 1(1):51-56.

Blank, D. E. \& Vieira, J. G. (2014). Caracterização físico-química e microbiológica de água de poços rasos do bairro Três Vendas, Pelotas-RS. Revista de Ciências Exatas e Engenharias, 24(1):2-20.

Branco, S. M. (2001). Água: origem, uso e preservação. São Paulo, São Paulo, Brasil: Moderna.

Brites, A. P. Z. \& Gastaldini, M. C. C. (2007). Avaliação da carga poluente no sistema de drenagem de duas bacias hidrográficas urbanas. Revista Brasileira de Recursos Hídricos, 12(4):211-221.

Brum, B. R., Oliveira, N. R., Reis, H. C. O., Lima, Z. M. \& Morais, E. B. (2016). Qualidade das águas de poços rasos em área com déficit de saneamento básico em Cuiabá, MT: Avaliação microbiológica, físicoquímica e fatores de risco à saúde. Holos, 2179-188.

Cerqueira, M. M. O. P., Picinin, L. C. A., Fonseca, L. M. \& Souza, M. R. (2006). Qualidade da água e seu impacto na qualidade microbiológica do leite. In A. J. Mesquita \& K. O. Coelho (Eds.), Perspectivas e avanços na qualidade do leite no Brasil (Vol. 1, pp. 273-290). Goiânia, Goiás, Brasil: Talento.

CETESB - Companhia de Tecnologia e Saneamento Ambiental. Qualidade das águas superficiais no Estado de São Paulo. São Paulo: CETESB, 2011. 342p.

Chagas, A. C. S. \& Veríssimo, C. J. (2008). Principai s enfermidades e manejo sanitário de ovinos. Embrapa Pecuária Sudeste, 1(1):70.

Coelho, C. R. (2001). Estudo hidrogeológico do aquífero quartzítico da Serra das Areias. Universidade do Vale do Rio dos Sinos-UNISINOS, RS, 64p. 2001. (Vol. 1, pp. 1-64). Rio Grande, Rio Grande do Sul, Brasil: Universidade do Vale do Rio dos Sinos.

Colvara, J. G., Lima, A. S. \& Silva, W. P. (2009). Avaliação da contaminação de água subterrânea em poços artesianos no sul do Rio Grande do Sul. Brazilian Journal of Food Technology, 211-14.

Cunha, A. H., Tartler, N., Santos, R. B. \& Fortuna, J. L. (2010). Análise microbiológica da água do rio Itanhém em Teixeira de Freitas-BA. Revista Biociências, 16(2):86-93.

Giatti, L. L., Rocha, A. A., Santos, F. A. d., Bitencourt, S. C. \& Pieroni, S. R. M. (2004). Condições de saneamento básico em Iporanga, Estado de São Paulo. Revista de Saúde Pública, 38571-577. 
Godinho, V. M. (2010). Investigação de bactérias patogênicas por técnicas moleculares em um sistema de tratamento de esgotos composto por reator UASB e lagoas de polimento. $\mathrm{PhD}$, Universidade Federal de Minas Geraais, Belo Horizonte, Minas Gerais, Brasil.

Holanda, J. S., Amorim, J. R. A., Ferreira Neto, M., Holanda, A. C. \& Sá, F. V. S. (2016). Qualidade da água para irrigação. In H. R. Gheyi, N. Dias, C. F. Lacerda \& E. Gomes Filho (Eds.), Manejo da salinidade na agricultura: Estudo básico e aplicados. Fortaleza, Ceará, Brasil: INCTSal.

Koch, F. F., Kauffmann, C., Bica, J. B., Adami, F. S., Stevens, J. F., Eckhard, C. L., . . Oliveira, E. C. (2017). Análise de água superficial para consumo humano em um município do Rio Grande do Sul. Revista Caderno Pedagógico, 14(1):36-50.

Llamas, M. R. \& Custodio, E. (1982). Hidrologia subterránea (Vol. 1). Barcelona, Spain: Ediciones Omega.

Madruga, F. V., Reis, F. A. G. V., Medeiros, G. A. \& Giordano, L. (2008). Avaliação da influência do Córrego dos Macacos na qualidade da água do rio Mogi Guaçu, no Município de Mogi Guaçu-SP. Engenharia Ambiental, 5(2):152-168.

Narciso, M. G. (2003). Gerenciamento ambiental na Serra das Areias-análise espacial e temporal da área de influência do aqüífero da Serra das Areias. Master of Science, Universidade do Vale do Rio dos Sinos, São Leopoldo, Rio Grande do Sul, Brasil.

Nass, D. P. (2002). O conceito de Poluição. Revista Eletrônica de Ciências, 131-3.

Oliviera, A. S., Santos, D. C., Oliveira, E. N. A., Brito, J. G. \& Lima, J. W. S. (2012). Qualidade da água para consumo humano distribuída pelo sistema de abastecimento público em Guarabira-PB. Revista Verde de Agroecologia e Desenvolvimento Sustentável, 7(2):199-205.

Ribeiro, L. \& Benedetti, E. (2012). A importância da qualidade da água na nutrição de ruminantes. Cadernos de Pós-Graduação da FAZU, 2.

Richter, C. A. \& Azevedo Netto, J. M. (2003). Tratamento de água: tecnologia atualizada. São Paulo, Brasil: Edgard Blucher.

Saling, C., Gräff, A., Oliveira, E. C. \& Böckel, W. J. (2017). Avaliação da qualidade da água de poços rasos no município de Colinas-RS. Tecno-Lógica, 21(2):59-64.

Schneider, R. N., Nadvorny, A., Santos, M. A. A. \& Schmidt, V. (2008). Caracterização da microbiota mesófila aeróbia de águas superficiais e subterrâneas da microbacia do Lajeado Suruvi. Acta Scientiae Veterinariae, 36(1):7-12.

Silva, L. L., Goulart, A. T., Melo, C. \& Oliveira, R. d. C. W. (2006). Avaliação microbiológica, química e físico-química da contaminação no Rio Paranaíba. Sociedade \& Natureza, 18(34):45-62.

Silva, R. C. A. \& Araújo, T. M. (2003). Qualidade da água do manancial subterrâneo em áreas urbanas de Feira de Santana (BA). Ciência \& Saúde Coletiva, 81019-1028.

Silveira, G. D., Silva, C. D., Irion, C. A. O., Cruz, I. C. \& Retz, E. F. (2003). Balanço de cargas poluidoras pelo monitoramento quali-quantitativo dos recursos hídricos em pequena bacia hidrográfica. Revista Brasileira de Recursos Hídricos, 8(1):5-11.

Xavier, C., Gonzales-Barron, U., Paula, V., Estevinho, L. \& Cadavez, V. (2014). Meta-analysis of the incidence of foodborne pathogens in Portuguese meats and their products. Food Research International, 55311-323. doi: http://dx.doi.org/10.1016/j.foodres.2013.11.024

Recebido: 11 de julho, 2019.

Aprovado: 2 de setembro, 2019.

Publicado: 8 de novembro, 2019.

Licenciamento: Este artigo é publicado na modalidade Acesso Aberto sob a licença Creative Commons Atribuição 4.0 (CC-BY 4.0), a qual permite uso irrestrito, distribuição, reprodução em qualquer meio, desde que o autor e a fonte sejam devidamente creditados. 